\title{
Analysis of the Dual-phase Steel DP500 Stress-strain Characteristics During the Plane Shear Test
}

David Koreček (0000-0003-2110-2746), Pavel Solfronk (0000-0002-8310-6825), Jiř́ Sobotka (0000-0002-65696593)

Faculty of Mechanical Engineering, Technical University of Liberec. Studentská 2, 46117 Liberec. Czech Republic. E-mail: david.korecek@tul.cz, pavel.solfronk@tul.cz, jiri.sobotka@tul.cz

Nowadays, the tendency to survey and accelerate technological processes in order to increase production efficiency on the one hand and to reduce the ecological impact of production on the environment on the other hand is increasingly prevailing. These aspects encourage both the applilcation of mathematical modelling of production processes and utilization of new material types ensuring sufficient strength and ductility while reducing the overall weight of the final asembly. This paper focuses on investigation and evaluation of the mechanical properties of the material under plane shear stress conditions. Specifically, it concerns the testing of a dual-phase high-strength steel DP500 (designation according to EN 10346) having structure based on a ferritic-martensitic matrix. The test material is loaded by means of a testing machine with a continuous static load and condition of the plane shear stress is achieved due to the geometry of the test specimen (ASTM B831). In the experimental part of this paper, plane shear tests are performed to determine the basic mechanical properties and stress-strain characteristics of the material with respect to the given loading conditions. These determined parameters and material characteristics can be further used as important input data to improve results of the numerical simulations regarding the aspect of metal forming technologies - basically stamping process.

Keywords: High Strength Steel, Sheet Metal Forming, Plane Shear Test, Shear Stress State, Mechanical Properties

\section{Introduction}

One of the fast and dynamically developing branches of industry today is certainly the automotive sector. This aspect necessarily encourages the acceleration of production processes, increasing work efficiency and the introduction of new types of materials to improve processing characteristics on the one hand, but above all to improve the final product characteristics on the other. The application of the strength steels in the automotive industry is nowadays an inherent part of the production process, where these materials are taken into account due to their high strength while maintaining the relatively favourable processing properties. They are used for the production of various car-body components, safety reinforcements and as part of the deformation zones in the car body. The use of these materials is a logical step linked in particular to the requirements about reduction the specific weight of cars, which leads to a reduction of the ecological impact on the environment.

However, tendency to use these types of materials brings with it certain pitfalls, especially in the production process. Nowadays, high demands are placed on sheet metal stampings, especially in terms of strength, surface quality and dimensional accuracy of the final product. A very important condition for the entire production process and the achievement of these required properties is the correct solution and description the deformation of the given part during its production. These desired resultant properties are greatly influenced not only by the shape of part to be manufactured, but also by the type of material chosen for its prodcution. An integral part of a correct and efficient technological procedure for the production of stamping having the appropriate shape and desired quality is proper solution of selected material deformation. Achieving the required shape and dimensional accuracy of the sheet metal stamping is significantly linked to the correct prediction of the material springback. This undesirable phenomenon, which is an integral part of the deformation process and significantly influences the whole stamping process, must be eliminated by means of an ideal design of technological operations in the process, the relevant process parameters and, above all, the appropriate shape and dimensional correction of the stamping tools. The use of the mathematical simulation for the production process in the environment of numerical simulations is offered as one of the advantageous solutions for the prediction and subsequent correction of the entire production process with regard to technological operations, process parameters and used materia. This issue is very closely related to the correct choice of mathematical computational material models and to have valid and accurate results, it is necessary to ensure 
correct input material data. In order to achieve the best possible accuracy of the numerical simulation results, it seems advantageous to apply advanced computational models that better describe the deformation process and the subsequent springback of the material. On the other hand, these require the use of advanced mechanical testing to ensure the appropriate characteristics. This paper is devoted to the mechanical testing of the dual-phase steel DP500 under plane shear stress conditions. The parameters and material characteristics measured during this type of loading can be further used as important input to numerical simulations, which through the aforementioned computational models will provide a more detailed and accurate description of the entire sheet metal stamping process. The following chapters focus on the description and evaluation of this type of mechanical material testing [1-9].

\section{Plane shear test}

This test is used to simulate a shear stress state just in one shear plane. During this test, the material in the form of a tesign sample is subjected to a shear load, which occurs in the form of a plane single shear stress state (American Standard ASTM B831). This stress state is achieved here by the geometry of the shear test specimen that is shown in Figure 1. This test specimen is loaded during the test with a continuously increasing force arisng from the translational movement of the testing jig clamps. The test is carried out until the fracture of specimen, i.e. until a cracks appear in the single shear zone of test specimen [7-14].

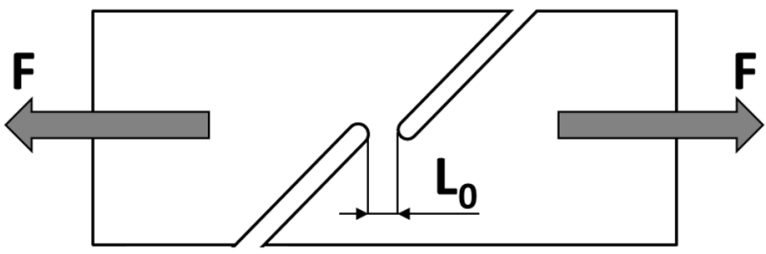

Fig. 1 Basic shear loading of the test specimen at plane shear test (ASTM B831)

In order to carry out the shear test, it was first necessary to realize the preparation fot he test specimens having the required geometry and dimensions (see ASTM B831, 2005). These testing specimens were produced by the waterjet cutting so that the specimens geometry would not be affected by the thermal conditions. Test specimens were prepared in the chosen directions as $0^{\circ}, 45^{\circ}$ and $90^{\circ}$ with respect to the rolling direction of the processed sheet. Owwn test was carried out on device TIRATest 2300, where the test specimen was clamped by using mechanical grips and subjected to uniaxial tensile loading. Whole course of the test was recorded by means of a strain gauge force sensor mounted on the crossbar of testing device and by the contact-less pptical system from company
Sobriety Ltd. Illustration of the shear test concept is shown in Figure 2 [10-14].

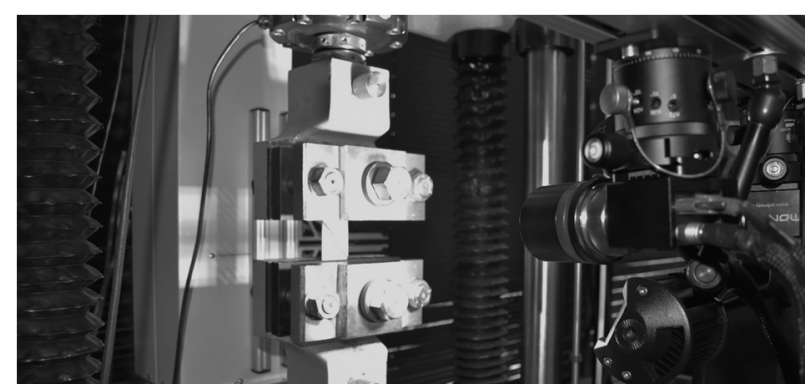

Fig. 2 Realization of the plane shear test on the testing device

In order to be able to optically measure the running test, it was necessary to apply on the test specimens surface a special pattern, on which own software creates a network of so-called facets and just movement of these facets is recorded and identified on the basis of the gray level assigned to each individual facet. The deformation of the test specimen (represented by the movement of the scanned facets) was recorded by two cameras during the test. Evaluation of this deformation on the scanning plane (shear zone) was subsequently performed by using the photogrammetric method in the software Mercury RT. Example of the working environment in the software Mercury RT together with a illustration of the test specimen measured area can be seen in Figure 3 .

Deformation occurring in the scanned area was further evaluated by using the Von-Mises yield locus (see Equation 1), where were used the major strains along the principal directions. These major strains were recorded during the test and subsequently evaluated using the software Mercury RT $[15,16]$.

$$
\varphi_{v}=\sqrt{\frac{2}{3}\left(\varphi_{1}^{2}+\varphi_{2}^{2}+\varphi_{3}^{2}\right)}[-],
$$

Where:

$$
\begin{aligned}
& \varphi_{v} \ldots \text { Von-Mises strain [-], } \\
& \varphi_{1}, \varphi_{2}, \varphi_{3} \ldots \text { Major strains [-]. }
\end{aligned}
$$

By means of the evaluated deformation in the material thickness direction, it was also possible to quantify the actual thickness of the test specimen during the whole test and together with the recorded length change in the shear zone, it was possible to define and subsequently calcualte the shear stress and deformation on the shear plane of test specimen - this in the final graphs are shown dependeces shear stress vs true strain. In order to be able to use and define this measured dependence in the numerical simulation processes, it was necessary to mathematically describe such dependence. For this reason, the final stres-strain (hardening) curve, with respect to the measured data, was mathematically approximated uby sing so-called Krupkowski law (approximation) that is defined by equation $2[15,16]$. 


$$
\sigma=K .\left(\varphi_{p l}+\varphi_{0}\right)^{n}[M P a],
$$

Where:

$\sigma \ldots$ True stress $[\mathrm{MPa}]$,

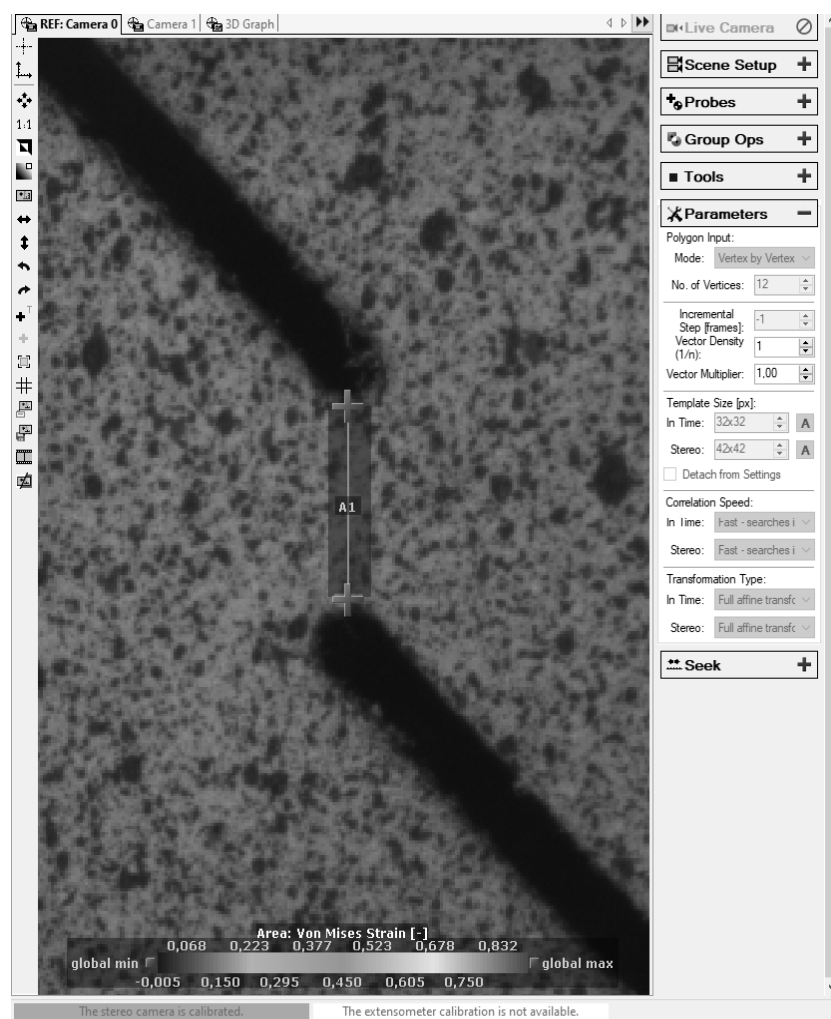

K...Strength coefficient [MPa], n...Strain hardening exponent [-], بpl...Plastic strain [-], $\varphi_{0} \ldots$ Offset of strain [-].

Fig. 3 Working environment of the software Mercury RT

\section{Results}

The recording and evaluation of the deformation in the scanned area (shear zone) of the test specimen was performed using the contact-less optical photogrammetry method in the software Mercury RT, as described above. Own recording and course of deformation during the test under shear loading conditions in the working environment of the given software is illustrated in Figure 4, where can be seen the distribution of the major strain in the measured region on the left side and recorded values of revelant force on the right.
Subsequent complete processing and evaluation of the relevant data was carried out in software Origin 2020, where was possible to finally expressed the dependence of the actual shear stress acting in the shear plane of test specimen on the relevant deformation (stress-strain curve). These resultant stress-strain dependences with respect to the relevant rolling direction of the tested material are graphically represented in Figure 5 and selected mechanical values of the material arisng from the plane shear test (shear yield strength $\tau_{\mathrm{ps}}$, shear strength limit $\tau_{\mathrm{s}}$ ) are summerized in Table 1.

Tab. 1 Selected mechanical properties of Dual Phase Steel DP500 and approximation coefficients

\begin{tabular}{|c|c|c|c|c|c|}
\hline Rolling direction $\left[{ }^{\circ}\right]$ & $\tau_{\mathrm{ps}}[\mathbf{M P a}]$ & $\tau_{\mathrm{s}}[\mathbf{M P a}]$ & $\mathbf{K}[\mathbf{M P a}]$ & $\mathbf{n}[-]$ & $\varphi_{0}[-]$ \\
\hline 0 & 318.20 & 490.26 & 630.56276 & 0.11014 & 0.00401 \\
\hline 45 & 331.09 & 460.77 & 534.67822 & 0.07098 & 0.00304 \\
\hline 90 & 387.45 & 468.09 & 576.34634 & 0.08725 & 0.00492 \\
\hline
\end{tabular}



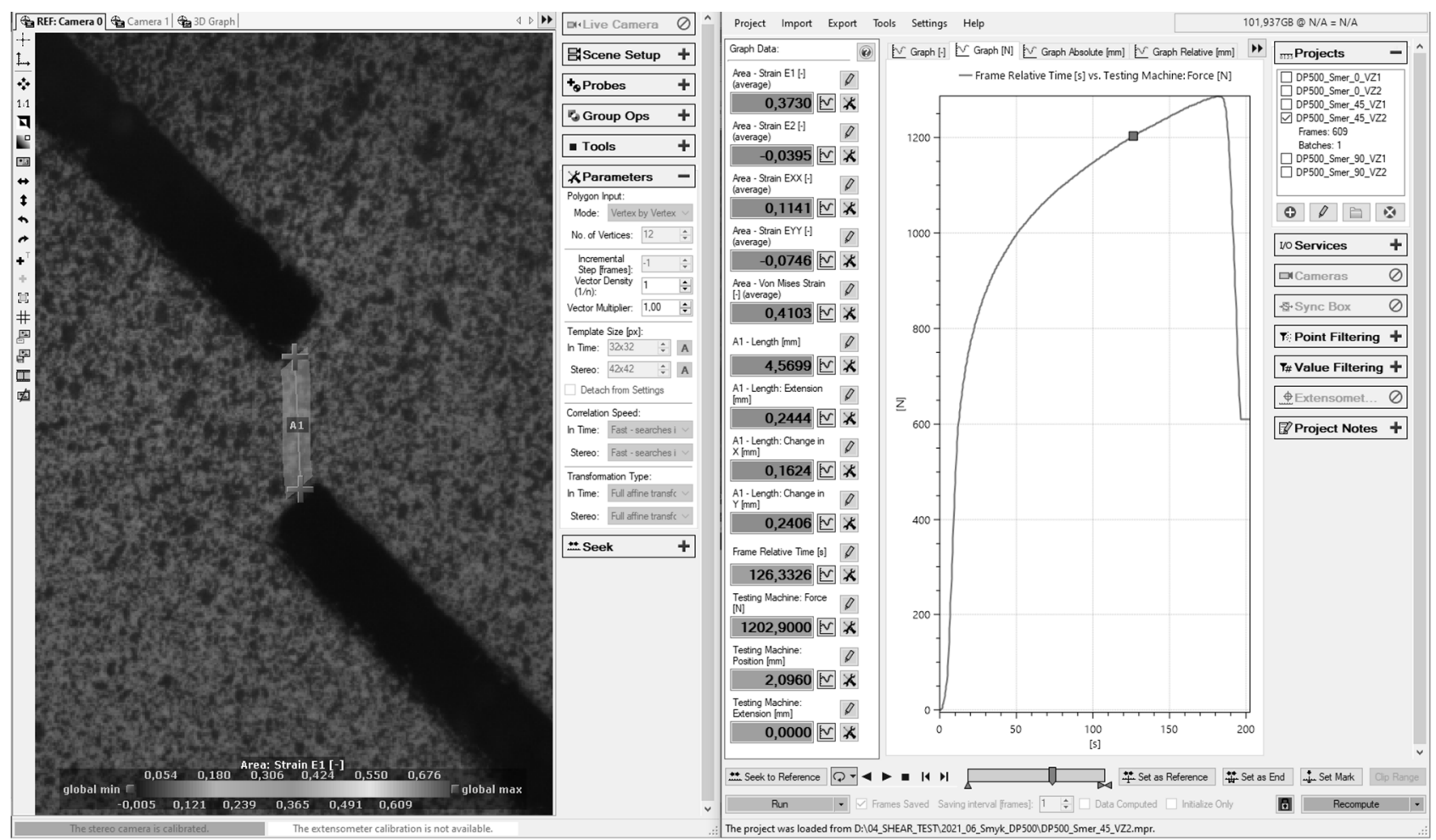

Fig. 4 Vizualization of major strain during the plane shear test in the working environment of software Mercury RT

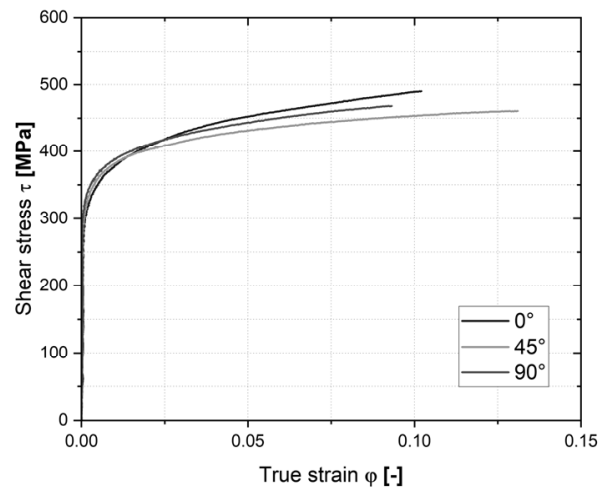

Fig. 5 Shear stress vs. strain for the individual rolling directions $0^{\circ}, 45^{\circ}$ a $90^{\circ}$

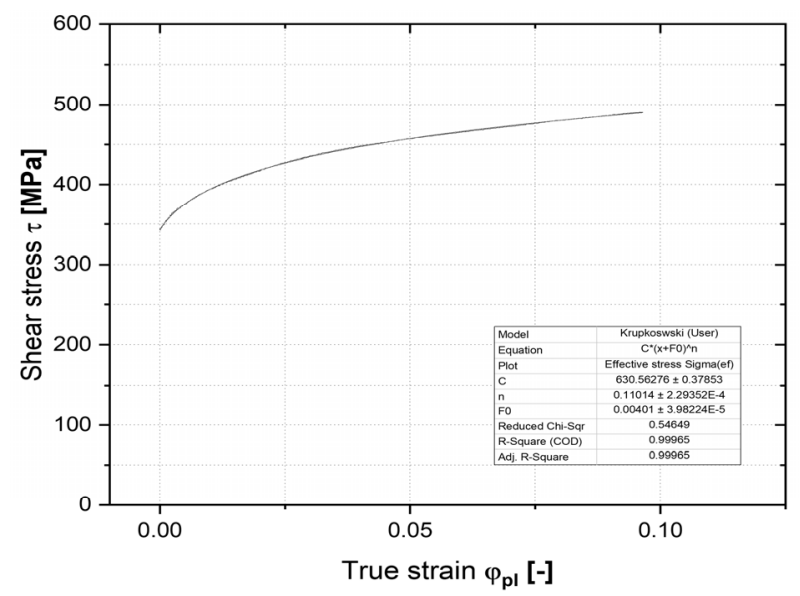

Fig. 6 Krupkowski law (approximation) of the stress-strain curve for chosen rolling direction $0^{\circ}$
Mathematical approximation of the material hardening curves (stress-strain curves) according to Krupkowski is for the chosen rolling direction $0^{\circ}$ illustrated in Figure 6 and values of the approximation coefficients $\mathrm{K}, \mathrm{n}$ and $\varphi 0$ obtained from the own approximation are subsequently shown in Table 1 for the individual rolling directions $0^{\circ}, 45^{\circ}$ and $90^{\circ}$.

\section{Conclusion}

The aim of this paper was to characterize and classify the mechanical properties of the dual-phase steel DP500 under the condition of loading the test specimen by the planr shear stress state. Testing under these conditions was carried out in order to determine the stress-strain characteristics of the selected material (DP500) under the given loading method. Resulting mechanical properties of the material under shear loading and dependence of the shear stress on the corresponding deformation are shown and described in the chapter above. These determined material characteristics, which were "mathematized" by the Krupkowski approximation, can be applied in the future to the metal forming numerical simulation and can be used for a more accurate definition of the material computational model in these numerical simulations. Thus, to improve the validity of the numerical simulations results in light of deformation during a given forming process and also the subsequent springback of the material. 


\section{Acknowledgement}

This work was [partly] supported by the Student Grant Competition of the Technical University of Liberec under the project No. SGS-2019-5046.

\section{References}

[1] DAVIES, G. Materials for Automobile Bodies. Oxford: Butterworth-Heinemann, 2003. s. 277. ISBN 0-7506-5692-1.

[2] KUČEROVÁ, L., TICHÁ, I. AND STEHLÍK, A. Effect of various heat and thermo-mechanical treatments on low alloyed CMnAlNb high strength steel. Manufacturing Technology, 2021, vol. 21, iss. 6, p. 824-828.

[3] CHOVANEC, A., BREZNICKÁ, A. Some aspects of a manufacturing process simulation. Manufacturing Technology, Vol. 17(3), pp 319-325. ISSN 1213-2489.

[4] HAJSMAN, J., KUCEROVA, L. AND BURDOVA, K. Comparison of high strength steels with different aluminium and manganese contents using dilatometry. Manufacturing Technology, 2020, vol. 20, iss. 4, p. 436-441.

[5] SU, CHUNJIAN, WANG, XUETAO. Sprinkback Research of $\mathrm{V}$-type Sheet Metal forming based on the Adjustable Drawbead and Variable Blank-holder Force Cooperative Control Technology. Manufacturing Technology. Vol. 14. pp 618-625. ISSN ISSN 1213-2489.

[6] WANG, Yan-Bo, Yi-Fan LYU, Yuan-Zuo WANG, Guo-Qiang LI a J. Y. RICHARD LIEW. A reexamination of high strength steel yield criterion. Construction and Building Materials [online]. 2020, 230, 116945. ISSN 0950-0618. Available from: doi:10.1016/j.conbuildmat.2019.116945

[7] MOĆKO, Wojciech, Adam BRODECKI a Joanna RADZIEJEWSKA. Effects of pre-fatigue on the strain localization during tensile tests of DP 500 steel at low and high strain rates. The Journal of Strain Analysis for Engineering Design [online]. 2015, 50(8), 571-583. ISSN 0309-3247. Available

from: doi: $10.1177 / 0309324715599132$

[8] AMARAL, Rui, Abel D. SANTOSA a A. B. LOPES. Mechanical properties determination of dual-phase steels using uniaxial tensile and hydraulic bulge test. Ciência \& Tecnologia dos Materiais [online]. 2017, 29(1), Materiais 2015, e239-e243. ISSN 0870-8312. Available from: doi:10.1016/j.ctmat.2016.06.007

[9] SHENGHUA, Wu, Nannan SONG, Abel SANTOS, Francisco ANDRADE PIRES a Rui AMARAL. FORMABILITY PREDICTION FOR DUAL PHASE STEEL SHEETS. 2016.

[10] DENTI, L. Additive Manufactured A357.0 Samples using the laser powder bed fusion technique: Shear and tensile performance. $\mathrm{Me}$ tals. 2018, vol. 8, no. 9 .

[11] ZHANG, Peng, Michael P. PEREIRA, Buddhika ABEYRATHNA, Bernard F. ROLFE, Daniel E. WILKOSZ a Matthias WEISS. Improving the shear test to determine shear fracture limits for thin stainless steel sheet by shape optimisation. International Journal of Mechanical Sciences [online]. 2019, 164, 105116. ISSN 0020-7403.

Available from: doi:10.1016/j.ijmecsci.2019.105116

[12] YANG, Bingen. 5 - Stress Analysis in Two-Dimensional Problems. In: Bingen YANG, ed. Stress, Strain, and Structural Dynamics [online]. Burlington: Academic Press, 2005 [vid. 2022-0128], s. 135-156. ISBN 978-0-12-787767-9. Available from: doi:10.1016/B978-0127877679/50006-4

[13] PEIRS, Jan, Patricia VERLEYSEN a Joris DEGRIECK. Experimental Study of the High Strain Rate Shear Behaviour of Ti6Al4V. Applied Mechanics and Materials [online]. 2011, 82. Available from: doi:10.4028/www.scientific.net/AMM.82.130

[14] WEI, L. Identification of strainrate dependent hardening sensitivity of metallic sheets under in-plane biaxial loading. Mechanical engineering. INSA de Rennes, 2015. Wuhan University of Technology, March 2015.

[15] YIN, Q., et al. An experimental and numerical investigation of different shear test configurations for sheet metal characterization. International Journal of Solids and Structures. 2014, vol. 51, no. 5 , pp. $1066-1074$.

[16] HOSFORD, W.F., CADDEL, R. Metal Forming (Mechanics and Metallurgy). 3rd ed. New York: Cambridge University Press, 2007. 